\title{
INFLUÊNCIA DA INDÚSTRIA FARMACÊUTICA \\ NA POLITICA DE MEDICAMENTOS, SEGUNDO OS PROFISSIONAIS DE SAÚDE
}

Maria Jalma Rodrigues Santana Duarte *

\begin{abstract}
RESUMO - O estudo realizou-se em quatro hospitais universitários públicos do Estado do Rio de Janeiro, no período de julho de 1986 a agosto de 1987. Visou à identificação da influência da indústria farmacêutica no atual regime político, social e econômico do País, concernente aos medicamentos. Aplicou-se o método descritivo, a pesquisa transversal e o "survey" junto à 1680 profissionais de saúde, (dentistas, enfermeiros, farmacêuticos e médicos). Constatou-se que a maioria não utiliza a RENAME da CEME como referência para a prescrição de medicamentos. Entre as promoções oferecidas pela indústria farmacêutica, prevalecem o patrocínio de eventos científicos, amostras grátis de medicamentos, passagens e estadias em hotéis e os prêmios en concursos científicos, como preferenciais da amostra adotada. Diante da questão da indústria farmacêutica a maioria foi favorável à sua influência na política de medicamentos considerando-se estes resultados propõe-se a divulgação da RENAME da CEME como referência de medicamentos mais seguros para a comunidade de saúde e a população em geral.
\end{abstract}

ABSTRACT - This study was performed in four public universitary hospitals in the State of Rio de Janeiro between July, 1986 and August 1988. Among the aims, it has been determined the identification of influencies of pharmacy industry in today's political, social and economic regimen in Brazil referring to medicines. Descriptive method, transversal research and group study (survey) was applied to 1,680 health professionals among dentists, nurses, pharmacists and physicians. The results showed that the majority doesen't use RENAME from CEME as a reference im medicine prescription and laboratory promotions as scientific events support, medicine free samples, fares and hotel expenses and prize in scentific competitions are the promotions that stayed on the preference of the sample. Considering the choice theory that eliminates the possibility of customer's indifference, the sample for pharmacy industry question stated, the majority, "for" its influence in medicine politics. Among many suggestions, it has been proposed the divulgation of RENAME from CEME as a better secure reference both for health staff and population.

\section{INTRODUÇÃO}

A indústria farmacêutica na atualidade constitui, segundo EVANS ${ }^{11}$, o exemplo clássico de desnacionalização conseqücnte do domínio do mercado nacional pelas empresas estrangeiras e subsidiárias. O volume de vendas de medicamentos é um dos maiores do mundo ocupando o 6o lugar no mercado mundial. Pérmanentemente são lançados produtos novos, sem levar em conta as necessidades da população, mas tão somente, os interesses de seus mercildos de origem. Para garantir uma posição de monopólio, a propaganda tem um papel importante facilitando inclusive o autoconsumo indiscriminado. Os fabricantes de medicamentos, cada vez mais interessados em conquistar o espaço de vendas, utilizam técnicas capazes de influenciar o comportamento dos profissionais de saúde que atuam nas instituições e na comuni-

\footnotetext{
* Livre Docente em Enfermagem de Saúde Pública - UERJ Doutor em Saúde Pública. ENSP - FIOCRUZ-RJ
} 
dade em geral.

É fato que o mercado consumidor de produtos farmacêuticos se mantém como decorrência das políticas de saúde e conseqëntemente das organizações das instituições e das práticas médicas.

TEMPORÃO ${ }^{19}$ revela a existência de um mercado potencial com aumento progressivo em função dos programas governamentais, extensão de cobertura, incorporando parte da população ao mercado de bens e serviços produzidos pelo complexo médico-industrial. Para ampliar, cada vez mais o seu mercado de vendas, a indústria farmacêutica utiliza uma prática de cura que valoriza a patologia em detrimento da saúde.

O mercado brasileiro consumidor de medicamentos basicamente é constituído por numerosas instituições de saúde dos setores público e privado.

LANDMANN $^{12}$ adverte que $\mathrm{O}$ governo mantém os lucros dessa indústria quando custeia o setor privado. Cita como exemplo o volume de mais de setenta por cento de seus recursos repassados por serviços prestados pelo setor privado contratados pelo Instituto Nacional de Assistência Médica e Previdência Social (INAMPS).

Para GENTILE DE MELLO ${ }^{14}$, a ação estatal amplia as dimensões medicalizadoras do consumo de medicamentos, ao mesmo tempo em que favorece o mercado de medicamentos ineficazes, inúteis e perigosos, além de tudo, muito caros.

Para MURAD, citado por GENTILE DE MELLO $^{14}$ do total de medicamentos consumidos no Brasil, trinta por cento efetivamente beneficiam a saúde da população; vinte por cento prejudicam mais do que beneficiam; enquanto que cinquenta por cento se destina, exclusivamente, a produzir lucros financeiros aos seus fabricantes.

\section{Justificativa}

As razões que levaram a autora ao estudo do tema referem-se à alguns aspectos profissionais do enfermeiro relativos ao seu trabalho e às mudanças decorrentes de sua prática. $O$ que se observa nessa prática são muitas indefinições, mais do que a possibilidade de objetivar a assistência de enfermagem fundamentada nos conhecimentos técnicos e científicos, isentos de contradições. Na diversificação de suas atividades específicas, incluem-se: administrar medicamentos prescritos, dar prosseguimento a prescrições anteriores, substituir os medicamentos por similares, suspendê-los ao apresentarem reações indesejáveis, orientar quanto à apresen- tação, dosagem, ação e aplicação por diferentes vias de introdução.

Além disso, cabe ao enfermeiro a "prescrição de medicamentos estabelecidos em programas de saúde pública e em rotina aprovada pela instituição de saúde, a aplicação de anestesia local, quando necessária à realização de episiotomia e episiorrafia".*

Vale registrar que a Enfermagem de Saúde Pública tem como finalidade a atenção individual, familiar e comunitária, significando que as suas ações se fundamentam nas necessidades de saúde da coletividade em seu conjunto. Quanto ao âmbito dos problemas, a Enfermagem de Saúde Pública não se limita a cuidar do indivíduo e sua famflia nas necessidades de seus casos isoladamente. Preocupa-se, evidentemente, com todos os fatores relacionados à saúde, como se distribuem e como afetam a qualidade de vida da população.

No que concerne aos medicamentos, a sua distribuição no mercado de vendas e as estratégias adotadas pela indústria farmacêutica favorecem cada vez mais, o consumo através de seu uso indiscriminado. Para tanto, esta indústria conta com a intermediação dos profissionais de saúde, inclusive o enfermeiro que muito contribui em função de sua prática profissional.

Pela sua característica profissinal, é fato que o enfermeiro tem maior acesso ao cliente e seus familiares, além da comunidade. Por isso mesmo, detém excelente oportunidade de orientar sobre assuntos de saúde. Quanto ao uso de medicamentos são abordados os prejuízos do uso inadequado, bem como os riscos a que a população está exposta quando estes medicamentos são indicados por pessoas não qualificadas para essa finalidade.

Numa abordagem ética, o enfermeiro tem suas responsabilidades fundamentais nas relações dos profissionais entre si, com seus clientes e com a comunidade.

"Porque a Enfermagem é perfeita forma de projeção do Bem ao nível do Homem. Sua Deontologia é o tratado onde se encontram os princípios e deveres que orientam e conduzem a atividade profissional, para que se mantenha sintonizada com a própria Enfermagem, e, em conseqüência, com o próprio Bem."

No Código de Deontologia de Enfermagem estão registrados:

“Art. 9o - É proibido ao enfermeiro:

* Lei no 7498/86 - Diário Oficial da União, 26 de junho de 1986 
X - emprestar seu nome para propaganda de medicamento ou outro produto farmacêutico, tratamento ou equipamento hospitalar, ou publicidade de empresa industrial ou comercial com atuação nesses ramos;

XII - receber, de laboratório, entidade de assitência à saúde ou estabelecimento congênere e de empresa industrial ou comercial, comissão, remuneração ou vantagem que não corresponda a serviço efetivamente prestado;

XVIII - administrar medicamento sem indicação do nome ou fórmula ou identificado apenas por número ou código, sem certificar-se, antes, da natureza das drogas que o compõem e da ausência de risco para o cliente". ${ }^{3}$

Sintonizada com as finalidades do setor saúde, sentiu-se a necessidade de contribuir para a reflexão dos enfermeiros, numa visão de sua prática assistencial notadamente, na vigilância epidemiológica sobre os danos que afetam à saúde coletiva.

Não obstante, a questão com o objeto da pesquisa que mais preocupou a autora, foi a definição metodológica para o entendimento quanto ao ato de prescrever numa visão idealista, ética e funcional. O primeiro ponto a considerar foi que a pesquisa deveria contemplar o social; e o segundo ponto, a de investigar o enfermeiro no conjunto dos profissionais de saúde em função do estudo da influência da indústria farmacêutica na política de medicamentos.

Por limitações metodológicas não foram abordadas as práticas dos profissionais de saúde na prescrição de medicamentos. Assim, o termo prescrição, genericamente, passou a ser compreendido como responsabilidades dos profissionais de saúde estudados, resguardando-se as suas especificidades (dentistas - prescrição restrita; enfermeiro - prescrição institucional e administração; farmacêutico - dispensação; e médico - prescrição universal):

Esta reflexão será o fio condutor que orientará os espaços cruciais do estudo como a indústria farmacêutica influência a política de medicamentos sob o ponto de vista de dentistas, enfermeiros, farmacêuticos e médicos. Na verdade, a forma indiscriminada e abusiva de me- dicamentos pode contar com a prática assistencial desses profissionais que não estando informados sobre as distorções existentes no setor, deixam-se influenciar pelas estratégias promocionais da indústria farmacêutica.

\section{Situação-Problema}

A literatura sobre a indústria farmacêutica no Brasil, não aprofunda quanto ao papel dos profissionais de saúde para o consumo dos medicamentos e como manipuladores da população para o autoconsumo. Os estudos existentes apontam a classe médica e abrangem contribuições importantes como a de FRENKEL e cols $^{12}$. com os conhecimentos sobre o estágio tecnológico da indústria e a perspectiva econômica. Estudos de CORDEIRO ${ }^{7}$ contribuem com o significado político e as suas articulaçōes com o autoconsumo e a prática médica. TEMPOR ÃO ${ }^{19}$ contemplando as estratégias de "marketing" da indústria de medicamentos enquanto objeto de análise, construiu nexos que hoje ligam a indústria farmacêutica, as práticas médicas, as agências publicitárias, o saber médico e os meios de comunicação de massa, enquanto estratégia de ampliação de consumo de medicalização da sociedade.

O estudo limita-se ao tema da indústria farmacêutica e a política de medicamentos sob a ótica dos profissionais de saúde, ou sejam, dentistas, enfermeiros, farmacêuticos e médicos.

Face ao exposto, pretende-se investigar as seguintes questões:

- Em que condições a Relação Nacional de: Medicamentos Essenciais da Central de: Medicamentos (RENAME da CEME) utilizada como referência na prática assitencial dos profissionais de saúde?

- Quais são as fontes de informações mais utilizadas pelos profissionais de saúde para a prescrição de medicamentos?

- Qual o posicionamento dos profissionais de saúde face à influência da indústria farmacêutica na política de medicamentos?

\section{Objetivos}

A proposta do trabalho é, a partir da bibliıgrafia específica, analisar aspectos relacionados a indústria farmacêutica no Brasil, questões relacionadas a dependência tecnológica e comercial, ao monopólio do mercado, ao problema social do consumo de medicamentos e a sua influência na política de medicamentos e no cornportamento dos profissionais de saúde atuando nas instituições e na comunidade. 
Os objetivos específicos compreendem:

- Relacionar as condições de utilização da RENAME da CEME de acordo com as categorias profissionais de saúde.

- Comparar as fontes de informações prioritárias adotadas pelos profissionais de saúde para a prescrição de medicamentos.

- Identificar a atuação da indústria farmacêutica no atual regime político, social e econômico do país, no que se refere aos medicamentos, segundo o posicionamento dos profissionais de saúde.

- Oferecer subsídios para ampliar a discussão das questões indústria farmacêutica e política de medicamentos junto aos profissionais de saúde.

\section{Hipótese}

A hipótese substantiva previu não haver diferença no posicionamento dos profissionais de saúde quanto à influência da indústria farmacêutica na política de medicamentos.

As hipóteses estatísticas derivadas da hipótese substantiva foram apresentadas em suas formas nula e alternativa:

$\mathrm{H}_{\mathrm{O}}$ - Não há diferença no posicionamento dos profissionais de saúde quanto à influência da indústria farmacêutica na política de medicamentos.

$\mathrm{H}_{1}$ - Há diferença significativa no posicionamento dos profissionais de saíde a favor e contra a influência da indústria farmacêutica na política de medicamentos.

\section{Referencial Teórico}

A moderna formulação da teoria das escolhas tem sido encontrada em trabalhos, como por exemplo os de DEBREU ${ }^{9}$ e NEUMANN ${ }^{21}$ que aplicam o método axiomático (axioma de preferência). Os modelos de escolhas em geral correspondem a dūas modalidades principais: modelos de escolha binária e modelos de escolha múltipla. Os primeiros estabelecem hipóteses sobre relações de preferência enquanto os últimos colocam restrições iniciais diretamente sobre o comportamento do agente em relação às condições do mercado.

UZAWA $^{20}$ demonstrou que ambos os sistemas são basicamente equivalentes, embora persistam ainda algumas dificuldades de interpretação. Concentrando atenção no grupo de modelos de escolha binária pode-se considerar de forma sumária que estes estabelecem um conjunto de hipóteses acerca do comportamento do agente, a partir dos quais são derivados os teoremas referentes às suas funções de demanda e oferta.

A análise foi conduzida tendo como re- ferência a teoria binária de escolhas. Os postulados básicos a serem utilizados neste estudo referem-se à comparabilidade das alternativas e continuidade de preferências (que implica na existência de indiferença) esta última eliminada pela teoria das escolhas, segundo DEBREU e NEWMANN ${ }^{21}$.

Face ao primeiro postulado, os profissionais de saúde terão que definir seu posicionamento diante das alternativas "contra" ou a "favor" da influência da indústria farmacêutica na política de medicamentos.

O segundo postulado, que se refere à eliminação da existência de indiferença, deverá confirmar que todos os profissionais de saúde têm um posicionamento diante do tema indústria farmacêutica e política de medicamentos, não sendo indiferente a essa questão.

\section{Organização do Estudo}

O estudo apresenta a literatura sobre o tema influência da indústria farmacêutica, dicotomizado em Política de Medicamentos e Profissionais de Saúde. Segue-se o relato da metodologia aplicada, especificando a análise de itens para a validação da escala' de atitude. Prosseguindo são analisados os resultados e apresenta a sua discussão, concluindo-se com as perspectivas, algumas Conclusões e Recomendações, pois não se pretende com esse estudo esgotar o tema.

\section{INFLUÊNCIA DA INDÚSTRIA FARMACÊUTICA}

A análise da situação atual da indústria farmacêutica implica em reconhecer a desorganização em que se encontra e a irracionalidade do emprego de medicamentos na população.

Segundo PRIETO ${ }^{18}$ a estrutura vigente no setor assume a forma de oligopólio diferenciado. Nele, encontraram-se as subsidiárias de empresas multinacionais dinâmicas e empresas locais que enfrentam dificuldades no processo de crescimento. Essas empresas dinâmicas tendem a operar apenas nas etapas finais de produção mantendo estreitos laços econômicos com os centros de decisão localizados no exterior. Os laboratórios nacionais, por sua vez, têm o interesse em contar com o suprimento de matériasprimas sem contudo possuir capacidade tecnológica, financeira e mercadológica para esses empreendimentos. Além disso, a maior parte dos insumos básicos são produzidos no exterior com os próprios recursos naturais nacionais e posteriormente importados com preços fixados pelas matrizes estrangeiras.

Hoje, a situação da indústria farmacêutica no país praticamente apresenta as mesmas de- 
pendências tecnológicas e contribui para os lucros e a expansão da indústria estrangeira sem ualquer exigência para o compromisso social.

A Divisão Nacional de Vigilância Sanitária de Medicamentos (DIMED), subordinada à Secretaria Nacional de Vigilância Sanitária é um órgão do Ministério da Saúde, exerce competência relativa aos Serviços de Análise Técnica, Registro e Cadastro; Fiscalização e Controle; e de Entorpecentes. O Decreto no 79 094, de janeiro de 1977, regulamenta a Lei no 6360 , de 23 de setembro de 1976, submete a sistema J،: vigilância sanitária os medicamentos, insu' os farmacêuticos, drogas. . . Os artigos e 'rágrafos contidos nesses Decreto deveriam diminuir as resistências identificadas no mercado de vendas para o consumo da população. Entretanto, a falta de fiscalização e venda indiscriminada de qualquer medicamentos geram estratégias que obscurecem todo o esforço governamental e de seus legisladores ${ }^{3}$.

O controle de medicamentos restritos contidos em uma lista consolidada e organizada pela Secretaria das Nações Unidas, aprovada em Assembléia Geral, em julho de 1984, não é respeitada no Brasil 4 .

A Central de Medicamentos (CEME) não representa a idéia que norteou a sua criação em 1971. Tinha o objetivo de regular a produção e distribuição de medicamentos oficiais ou a estes vinculados. Além disso, não produz seus próprios medicamentos como previa o Plano Diretor de Medicamentos, de 30 de julho de 1973. Atualmente, opera com quinze laboratórios oficiais, quinze laboratórios privados nacionais e trinta e dois multinacionais. Suas verbas são insifucientes para atender às necessidades da população carente e as exigências para a modernização do setor. Registra-se que a RENAME da CEME, elaborada pelo Conselho Consultivo da CEME e aprovada pelo Conselho Diretor nos termos da Resolução no 01/82, de 06 de agosto de 1982, indicar os produtos farmacêuticos essenciais, de eficiência e eficácia garantidas e de baixo custo, na prática assistencial, essa referência não é considerada pelos profissionais de saúde ${ }^{2}$.

\section{Na Política de Medicamentos}

As instituições de saúde são responsáveis pela utilização dos produtos farmacêuticos, equipamentos e instrumentos para a promoção de uma assistência moderna sem contudo preocupar-se com o bem-estar do cliente ou com a estabilidade da economia nacional. As indústrias que produzem esses produtos constituem o complexo médico-industrial responsável pelos benefícios e prejuízos na assistência à saúde da população brasileira.

O Brasil gasta uma média de dois bilhões de dólares anuais com o mercado de medicamentos que tem oitenta e seis por cento de sua produção em mãos de empresas internacionais segundo o Secretário da Medicina do Ministério de Saúde ${ }^{12}$.

O consumo de medicamentos, no presente, tornou-se uma prática que reproduz o modelo dos serviços de saúde. Os mecanismos de difusão, segundo $\mathrm{CORDEIRO}^{7}$, funcionavam através dos agentes de saúde, do médico em particular, e das agências de comercialização configurando como uma rede bastante complexa na qual o paciente $\varepsilon$ apreendido e inculcado em práticas de consumo, incluindo a automedicação.

A Organização Mundial de Saúde, em 1977 publicou uma lista de medicamentos essenciais tendo em 1979 sofrido uma revisão através da Resolução no 641, relacionou 243 medicamentos básicos, dos quais 203 essenciais e 40 complementares podem resolver quase que todos os problemas setoriais da prática médica. Supreendentemente, verdadeiros obstáculos impedem a utilização dos medicamentos relacionados cuja resistência dos médicos defendem a liberdade de prescrição das quarenta e sete mil especialidades farmacêuticas existentes no mercado estimadas em 1981 pela Secretaria Nacional de Vigilância Sanitária do Ministério da Saúde. Ressalte-se que a comissão da OMS, responsável pela organização da lista de medicamentos essenciais foi constituída de representantes do mundo médico: Estados Unidos, União Soviética, Brasil, França, Indonésia, Tunísia, Irā, Senegal. Esta comissão foi assessorada por representantes da OMS, da UNICEF, da Federação Internacional das Associações de Fabricantes Farmacêuticos e da Federação Farmacêutica Internacional. A lista inclui drogas de uso, até hoje sem controvérsia, largamente utilizadas e solidamente avaliadas. Não obstante, tanto a lista. da OMS, quanto a da CEME, não foram e não são divulgadas, nem há menor interesse das associações médicas para elaborar um projeto de racionalização para o uso de medicamentos apoiando a iniciativa das indústrias farmacêuticas para o aumento da quantidade de seus produtos $^{12}$.

A RENAME foi elaborada pela CEME visando a cobertura adequada de "fármacos de maior interesse para o cuidado preventivo, diagnóstico e terapêutico de cerca de noventa e cinco por cento do quadro nosográfico do país ${ }^{2}$.

\section{Nos Profissionais de Saúde}

O papel desempenhado pelos profissionais de saúde para a medicalização da sociedade é fundamental, ao mesmo tempo em que expande cada vez mais a comercialização de todos os 
produtos farmacêuticos novos lançados ao mercado nacional.

De acordo com GARRAFA ${ }^{13}$, as universidades brasileiras, com exceções, têm conduzido o processo de formação profissional de forma alienada face à realidade do mercado de trabalho. A universidade forma dentistas para o atendimento de uma clientela elitista, opondo-se às condições dominantes de subdensenvolvimento, que no momento são mais críticas devido aos índices de inflação que desequilibram o sistema econômico do país. Privilegia-se a assistência curativa e como conseqüência a assistência odontológica perde a qualidade por falta de orientação sistemática e adequada às necessidades de saúde da população. Acrescenta que os órgãos de classe têm sido insensíveis a essa questão, pois os problemas odontológicos da maioria dos brasileiros são os mesmos de cinco décadas passadas. Para garantir o direito da população em possuir "saúde bucal" o autor propõe entre outras medidas a revisão dos princípios que orientem a formação dos dentistas, visando ao fortalecimento da odontologia preventiva e a simplificação de uma prática assistencial. Para tanto, deveria substituir os recursos tecnológicos sofisticados, materiais e medicamentos, por recursos negadores do consumismo, atendendo à finalidade da profissão.

Os profissionais de enferrnagem, particularmente o enfermeiro, segundo DUARTE ${ }^{10}$, aceita esse novo papel acreditando ocupar um espaço técnico para melhor contribuir na assistência à saúde da população. Por outro lado, os benefícios oferecidos pelos fabricantes de medicamentos são recebidos pelas chefias de enfermagem favorecendo principalmente as entidades patrocinadoras de seus eventos culturais e científicos. Esse comportamento, que se desenvolve através dos tempos recentes, vai se reproduzindo pelas novas gerações de enfermeiros valorizando sem uma análise ćrítica a ação desordenada da indústria de medicamentos. Atualmente, empresas importantes contratam os serviços de enfermeiros para, a título de desenvolverem determinados setores, beneficam-se de sua formação e de sua inexperiência profissional ou mesmo de sua insatisfação pessoal. Na verdade, os enfermeiros desconhecem ou não se interessam pelas questões graves existentes em termos dos medicamentos e nessa medida são aderentes as instituições em que trabalham, limitando-se a seguir rigorosamente as prescrições médicas. Frequentemente essas prescriçōes feitas com as "marcas" de medicamentos, nome comercial do produto farmacêutico, são substituídas por outras "marcas" que quase sempre a sua composição é inadequada. As contradições identificadas na prática demonstram o despreparo do enfermeiro que por tradição e comodidade espelha-se no modelo imposto.

Considerando a formação do farmacêutics. é o profissional capacitado a dirigir o setor tecnológico farmacêutico, tornando-o mais independente das imposições das indústrias estrangeiras. Face ao consumo abusivo dos medicamentos $\mathrm{CUNHA}^{8}$ destaca a questão da profissionalização da farmácia. Atualmente, a assistência farmacêutica à comunidade é substituída por um esquema comercial de vendas de medicamentos, sendo desrespeitado o direito da população a uma assistência de qualidade. Sustenta que as atividades de dispensação de medicamentos sejam privativas do farmacêutico, o que deverá resultar no saneamento do setor.

Os medicamentos beneficiaram o tratamento do paciente se o médico que detem o conhecimento terapêutico e farmacológico indicasse o produto eficiente e eficaz. Ocorre que a indústria farmacêutica exerce forte pressão sobre êles desenvolvendo um processo de dúvidas sobre o conhecimento farmacológico e aspectos éticos dos medicamentos configurando-se a fragilidade na sua relação profissional com o paciente. TEMPORÃO ${ }^{19}$ descreve uma espécie de mútua dependência do médico e da indústria farmacêutica que ocorre através de "contato com os propagandistas de laboratório durante os anos de formação, que diariamente mantém contato com os estudantes nos hospitais de ensino; medicamentos utilizados em seus pacientes de enfermaria, conhecidos incialmente por seus professores ou instrutor de leito, que por sua vez também se guiam pelo nome da "marca"; prática empírica durante ois inúmeros estágios realizados em instituições de saúde, quase sempre sem supervisão. A farmácia hospitalar acaba interferindo sobre a prática de prescrição do futuro profissional e ao autocuidado e experiências pessoais anteriores com a doença e seu tratamento.

Para avaliar o empirismo do processo que o médico estrutura e define os medicamentos que utilizará em sua prática, BARROS' realizou uma pesquisa de opinião entre os médicos reunidos em um congresso realizado em Recife onde os resultados apresentaram como fonte de informação: artigos e revistas especializadas, recomendações de colegas especialistas, contatos com outros colegas, representantes de laboratórios, reuniões de trabalho, índice ou guia médico, propaganda em revistas especializadas, cursos de reciclagem, literatura ou propaganda distribuída, e congressos patrocinados por indústrias.

FRENKEL . Cols ${ }^{12}$, advertem que as fontes como artigos em revistas especializadas, congressos médicos, recomendações de especialistas, entre outras, não são necessariamente fontes independentes das firmas de produtos far- 
macêuticos, pois podem estar vinculadas as atividades promocionais das mesmas.

LANDMANN $^{17}$ enfatiza a existência da mútua dependência contínua que liga e garante a sobrevivência do médico e a industria farmacêutica que se reflete através do contato o camaradagem com o propagandista. Para conquistar a "boa vontade" as firmas oferecem além de presentes como blocos, agendas, receituários, adornos para casa ou consultório e até assinatura de revistas não-médicas e custeiam a realização de reuniões, a vinda de conferencistas que servem de instrumento institucional do consumo de especialidades farmacêuticas da indústria que financia seus trabalhos. Utilizam desde as técnicas tradicionais aos métodos mais modernos e para tanto, oferecem financiamentos e custeiam congressos seminários, simpósios, reuniões, jornadas médicas, de enfermagem, de odontologia, de farmacêuticos. Produzem, editam e distribuem literatura nacional e estrangeira demonstrando as vantagens das propriedades dos novos produtos.

Segundo GENTILE DE MELLO ${ }^{14}$, a indústria farmacêutica organiza concursos e institui pręmios e os participantes julgadores e laureados são os médicos. Além disso, publicam livros médicos e custeiam revistas de medicina, enfermagem, odontologia e farmácia.

\section{METODOLOGIA}

A metodologia compreende: método e técnica da pesquisa, seleção dos sujeitos, instrumentação, coleta de dados e tratamento estatístico.

\section{Método e Técnica da Pesquisa}

Realizou-se uma pesquisa descritiva a partir do método transversal e estudo de conjunto ("survey") com profissionais de saúde envolvidos com a questão de medicamentos, ou sejam, dentistas, enfermeiros, farmacêuticos e médicos.

A investigação abrangeu duas amostras não equivalentes quanto à randomicidade; a primeira visou a testagem do instrumento da coleta de dados e a segunda respondeu o questionário definitivo permitindo a testagem das hipóteses formuladas.

O estudo desenvolveu-se no período de julho de 1986 a agosto'de 1987, tendo sido utilizado como campo de pesquisa um hospital universitário particular (para o estudo do instrumento de coleta de dados) e os quatro hospitais universitários públicos situados o Estado do Rio de Janeiro. Inicialmente o projeto deste estudo previa a inclusão dos hospitais universitários particulares, entretanto, as direções dessas entidades (à exceção de uma) recusaram-se a participar da pesquisa alegando que o tema com- prometia o relacionamento comercial com a indústria farmacêutica.

Justifica-se a delimitação do campo da pesquisa aos hospitais universitários pelo fato do tema ter sido investigado, até o momento atual, em nível institucional e ter envolvido apenas o grupo médico, excluindo outros profissionais de saúde que também participam diretamente das questões subjacentes a essa temática. Por outro lado, a relevância do problema exige sua discussão no âmbito do ensino das ciências da saúde e o hospital universitário, uma das áreas da prática assistencial, deve ser o lugar do estudo e da crítica assistencial em seus aspectos técnicos-científicos, políticos-econômicos, sociais e éticos.

\section{Seleção dos Sujeitos}

Estabeleceu-se como população deste estudo o conjunto de profissionais de saúde - dentistas, enfermeiros, farmacêuticos e médicos lotados nos hospitais universitários e professores de campo de estágio das áreas correspondentes.

\section{Instrumentação}

Aplicou-se um questionário contendo dez questões de múltipla escolha e uma escala de atitude com trinta itens, sob a forma adaptada da escala de LIKERT com três graus.

As questões de múltipla-escolha que identi-', ficam os sujeitos expressam as variáveis: categoria profissional, função exercida e fonte(s) de renda da saúde e, ainda, as varáveis demográficas - sexo, faixa etária e estado civil.

As variáveis referentes às questões a serem investigadas compreendem a utilização da $\mathrm{Re}$ lação Nacional de Medicamentos da Central de Medicamentos (RENAME da CEME) na prática assistencial, ordem de utilização das fontes de informações consideradas na prescrição de medicamentos e ordem de preferência quanto às promoções das indústrias farmacêuticas dirigidas à área da saúde.

A escala de atitudes compreende trinta proposições que foram classificadas em três categorias - econômica, política e técnica - considerando seu conteúdo predominante face ao tema em estudo. As trinta proposições formuladas para compor a escala provisória foram examinadas por oito psicólogos especialistas em psicometria que julgaram a adequação e a pertinência de cada uma em relação aos objetivos propostos pela pesquisa.

A folha de resposta relaciona escala de três graus correspondendo às opções - "concordo, indeciso e discordo" - cuja posição, no instrumento, também foi sorteada para evitar a indução de respostas. 
A escala provisória foi testada, previamente, em vinte profissionais de saúde (cinco representantes de cada categoria especificada) de um determinado hospital geral, de grande porte, que recebe estagiários e professores supervisores dos quatro hospitais universitários públicos pesquisados. Além das instruções constantes do formulário os sujeitos foram orientado para justificar, por escrito, as razões das respostas em branco. A análise dos dados obtidos e todas as questões respondidas indicaram a permanência dos itens no instrumento.

Os procedimentos de validação aprovaram as proposições do instrumento de coleta de dados.

\section{Coleta e Apuração de Dados}

A abordagem individual dos sujeitos consistiu na exposição do objetivo da pesquisa e do instrumento de coleta de dados com a explicação de que o mesmo deveria ser respondido no local de trabalho e devolvido à pesquisadora ao término do plantão. Seguiu-se o mesmo procedimento na aplicação do questionário definitivo, sendo observada a escala de trabalho que definia as equipes dos diversos plantões. $\mathrm{Na}$ fase de coleta de dados, junto a amostra definitiva, a autora foi auxiliada por uma equipe de oito elementos, tendo sido designados dois para cada unidade hospitalar.

A análise crítica dos questionários respondidos eliminou $121(6,71)$ incoerentes, reduzindo a amostra definitiva para 1680 sujeitos, conforme está disposta na tabela que se segue:

Amostra Definitiva dos Profissionais de Saúde de acordo com a sua Categoria e Hospital

\begin{tabular}{|c|c|c|c|c|c|c|c|c|c|c|}
\hline Hospital & & & & & & & & & & tal \\
\hline $\begin{array}{l}\text { Categoria } \\
\text { Profissional }\end{array}$ & $\mathbf{F}$ & $\%$ & $\mathbf{F}$ & $\%$ & $\mathbf{F}$ & \% & $\mathbf{F}$ & \% & $\mathbf{F}$ & $\%$ \\
\hline Dentistas & 54 & 26,21 & 77 & 37,37 & 70 & 34,00 & 5 & 2,42 & 206 & 100,00 \\
\hline Enfermeiros & 107 & 27,87 & 115 & 29,95 & 126 & 32,81 & 36 & 9,37 & 384 & 100,00 \\
\hline Farmacêuticos & 11 & 9,49 & 53 & 45,69 & 47 & 40,51 & 5 & 4,31 & 116 & 100,00 \\
\hline Médicos & 236 & 24,22 & 285 & 29,27 & 365 & 37,48 & 88 & 9,03 & 974 & 100,00 \\
\hline
\end{tabular}

Os dados foram apurados por computação eletrônica, tendo sido utilizado o modelo com disco flexível, Sistema Operacional compatível com o CP/M e a linguagem do desenvolvimento foi o D. Base II.

Estabeleceu-se o seguinte critério de avaliação para respostas da escala de atitudes:

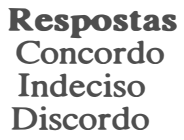

Respostas
Concordo
Indeciso
Discordo

A resposta. "concordo" recebeu ponto positivo, indicando a tendência "a favor" da influência da indústria farmacêutica na política de medicamentos e a resposta "discordo" recebeu ponto negativo, apontando a tendência "contra a essa influência".

Foi estabelecido o seguinte critério de avaliação global por questionários:

\author{
Pontos Atribuídos \\ 1 Prof Me Miriam Rima da Móbreas \\ 1 \\ Mat. UFPB - 6593
}


influência da indústria farmacêutica na política de medicamentos dada pela escala de atitudes.

A análise de itens baseou-se no teste $T$ de Student para verificar se os itens numa medida: a) estão relacionados a um conceito; b) têm o poder para discriminar entre sujeitos com graus alto ou baixo da característica a ser medida. $\mathrm{O}$. método apresenta um critério objetivo para. identificação e eleiminação das proposições "fracas" que podem interferir na estabilidade do instrumento definitivo.

\section{Conceituação de Termos}

DROGA - qualquer substância simples ou composta de variada origem e utilizada com variados fins, que administrada no organismo vivo em pequena quantidade pode produzir alterações somáticas ou funcionais ${ }^{b}$.

ESPECIALIDADE FARMACÊUTICA - todo medicamento preparado antecipadamente, apresentado sob uma embalagem particular, caracterizado por uma denominação particular ${ }^{6}$.

FARMACODINÂMICA - estudo da ação e do ef eito das substâncias no organismo ${ }^{6}$.

MATÉRIA-PRIMA - substância pouco elaborada imprescindível à fabricação do medicamento ${ }^{6}$.

MEDICAMENTO - toda substância ou composição de uso interno ou externo com finalidades curativas em função de doenças humanas ou animais ${ }^{6}$.

REMÉDIOS - semelhante a medicamentos ${ }^{6}$.

\section{CONDIDERAÇÕES FINAIS}

Face à Teoria das Escolhas que elimina a possibilidade da posição de indiferença do consumidor constatou-se que a maioria - 1025 (61.00\%) da amostra estudada, diante da questão da indústria farmacêutica, se colocou “a favor" de sua influência na política de medicamentos.

No grupo " "a favor" destacaram-se, por ordem decrescente de freqüência, os médicos, enfermeiros, dentistas e farmacêuticos. Nesse subconjunto os médicos representam a maioria, refletindo o modelo imposto de mediador do consumo de remédios, até por sua condição tradicional de prescrito mais frequente. No grupo "contra", representado pela minoria - 655 $(39.00 \%)$ dos profissionais de saúde que foram encontrados na mesma ordem decrescente de freqüência, já citada, predominando os médicos.

Constatou-se, também, que a maioria não utiliza a RENAME da CEME como referência para a prescrição de medicamentos. Nesse grupo é o enfermeiro quem menos conhece esta ertidade e os seus benefícios para a populaçã (, acompanhando dessa forma, o posicionamento dos demais profissionais de saúde.

Entre as promoções of erecidas pela indústria farmacêutica, prevalecem 'o patrocínio ce eventos científicos amostras grátis de medicamentos, passagens e estadas em hotéis e os prêmios em concursos científicos como preferenciais da amostra do estudo.

Considerando tais resultados, recorda-se que o progresso tecnológico na área da saúde tem contribuŕdo para o aumento dos custos dos serviços assistenciais porque utiliza novos medicamentos, equipamentos mais sofisticados e técnicas mais complexas e, obviamente, mais onerosas. Esse progresso tem por finalidade intríseca aumentar a qualidade de vida, entretanto se os medicamentos são falsificados ou não são submetidos ao controle de qualidade não of erecem a garantia e a segurança a que os pacientes têm direito.

A desorganização identificada no setor saúde revela o descompromisso das instituiçōes públicas e privadas e de seus profissionais ccim a população, tornando-se instrumento poderoso da expansão do mercado de medicamentos fabricados por indústrias estrangeiras. As instituições responsáveis pelo controle da produção, comercialização e apresentação de medicamentos continuam pressionadas pelas multinacion ais e pelos órgãos subordinados às suas políticas.

Os profissionais de saúde são cooptados pelo modelo dominante apresentando a tendência favorável à influência da indústria famacêutica.

Evidentemente, é indispensável e urgentes a definição de uma política de medicamentos sapaz de controlar a ganância de seus fabricantes. Devem ser adotadas medidas saneadoras visando à reorientação do mercado de vendas das mais de 47 mil especialidades farmacêuticas, 0 superfaturamento de medicamentos importaclos e proíbidos em seus países de origem. Assim como devem ser coibidas as práticas promocionais dos medicamentos que resultam em graves prejuízos à toda população.

Nessa medida, torna-se igualmente incispensável a ampla divulgação da RENAME da CEME referindo os produtos farmacêuticos cque podem merecer a confiança das autoridades sanitárias, bem como of erecer a segurança aos profissionais de saúde e à população, quanto aos remédios mais eficientes. Tudo isso pode servir de estratégia capaz de pressionar os profissionais de saúde e as autoridades sanitárias para tomada de decisões coerentes à realidade brasileira.

Tendo como principal motivação a melhuria da saúde da população brasileira, devem ser 
restabelecidas as medidas saneadoras que estabelecem uma política nacional de medicamentos capaz de cumprir com a finalidade social, ampliando a discussão do tema com os profissionais de saúde e a população através de seus legítimos representantes. Assim, o setor saúde mediante um desempenho responsável contribuirá para a racionalização do mercado de vendas das inumeras especialidades farmacêuticas existentes no mercado nacional. $\mathrm{O}$ resultado do esforço conjunto repercutirá em benefícios econômicos, além de proteger a saúde dos brasileiros.

Face ao exposto, recomenda-se ao enfermeiro que:

- ao identificar a questão de medicamentos como problema de saúde pública, participe mais ativamente na orientação da clientela, quanto aos riscos do uso de medicamentos indicados por pessoas não qualificadas para essa finalidade;

- pela sua característica profissional, tem maior acesso ao cliente e à comunidade contribua para a diminuição das iatrogenias e a resistência medicamentosa produzidas pelo uso inadequado de medicamentos;

- ao se ampliar a discussão do tema com os profissionais de saúde e a população, indicada como medida saneadora do uso indiscriminado de medicamentos como problema de saúde pública, não se encontre desinformado, em relação às distorções existentes no setor medicamentos:

- amplie o seu trabalho educativo junto à clien- tela para orientá-la sobre os riscos a que se encontra submetida ao usar medicamentos indicados por balconistas de farmácias e drogarias, ou por outras pessoas sem a devida qualificação;

- participe das discussões da questão de medicamentos como problema de saúde pública para contribuir criticamente sobre as estrategias adotadas pela indústria farmacêutica quanto ao aumento desordenado de seus produtos sem uma finalidade social;

- busque fortalecer o seu compromisso profissional quanto à promoção e proteção da saúde do cliente e da população em geral, não se deixando influenciar pelas práticas promocionais da indústria farmacêutica.

\section{ÀS ESCOLAS DE ENFERMAGEM}

- Incluam na sua programação curricular o estudo da questāo de medicamentos como problema de saúde pública permitindo aos futuros profissionais a reflexão sobre as contradições identificadas no setor.

\section{ÀS AUTORIDADES SANITÁRIAS}

- vislumbrem as possibilidades de restabelecer as medidas saneadoras previstas, retomando a discussão com os profissionais de saúde e a população sobre as impropriedades referentes à questão de medicamentos;

- procedam a distribuição da RENAME da CEME aos profissionais de saúde para que os mesmos possam controlar o uso desses medicamentos possibilitando, assim, a racionalização e a reorientação do mercado de vendas no que concerne a esta prática.

\section{REFERÊNCIAS BIBLIOGRÁFICAS}

1 BARROS, J.A.C. A medicalização da clientela previdenciária. Tese de Mestrado. Faculdade de Medicina da Universidade de São Paulo: 1982. 176p.

2 BRASIL, Ministério da Previdência e Assistência Social, de Saúde, e de Educação e Cultura. Portaria Interministerial no MPAS/MS/MEC 031982.

3 - Ministério da Saúde. Legislação Federal do Setor Saúde. MS. 1978.

4 - Ministério da Saúde. 8a Conferência Nacional de Saúde; relatório final. Brasßlia, 1986.

5 - Ministério do Trabalho. Conselho Federal de Enfermagem. Códigos Deontologia de Enfe agem. Processo Ético. Transgressōes e Penalidades. 1978.

6 CORBER T, C.E. Farmacodinamica. 3. ed., São Paulo: Artes Medicas, 1971.

7 CORDEIRO, H.A. Determinantes do conisumo de medicamentos. Tese de Mestrado. Instituto de Medicina Social da Universida de do Estado do Rio de Janeiro, 1978. $151 \mathrm{p}$.

8 CUNHA, B.C. de A. Saúde a prioridade esquecida. Petropolis: Vozes, 1987. $133 \mathrm{p}$.

9 DEBREU, G. Théorie de la valeur: analyse axiomatique de l'equilibre economique. Paris: Dunod, 1966. 121 p.
10 DUAR TE, Maria Jalma R.S. A indústria farmacêutica e suas conseqüências no mercado brasileiro. Monografia apresentada durante oCurso de Pós-Graduação em Saúde Pública na Escola Nacional de Saúde Pública da Fundação Oswaldo Cruz. Rio de Janeiro: 1986. 36 p.

11 EVANS. P. A triplice aliança; as multinacionais, as estatais e o capital nacional no desenvolvimento dependente brasileiro. $2^{\mathrm{a}}$ ed. Rio de Janeiro: Zahar, 1980.

12 FRENKEL e Cols. Tecnologia e competiçāo na indústria farmaceutica brasileira. Rio de Janeiro: FINEP 1978. 209 p.

13 GARRAFA, V. Contra o monopólio da saúde. Rio de Janeiro: Achiamé, 1984. 143 p.

14 GEN TILE DE MELLO, C. A medicina e a realidade brasileira. Rio de Janeiro: $137 \mathrm{p}$.

15 GUILFORD, J.P. Psychometric methods. New York: MacGraw-Hill. 1954. 392 p.

16 HESSES, J. Filosofia dos Valores. 4. ed., Coimbra: Armenio Amado. 1984. 347 p.

17 LANDMANN, J. Evitando a saúde \& promovendo a doença: O Sistema Nacional da Saúde. Rio de Janeiro: Achiame, 1982. 
18 PRIE TO, C. Radiografia das Multinacionais. Rev. de Administraçâo Pública. Rio de Janeiro: 10 (1): 90-106, jan./mar., 1976

19 TEMPORÃO, J.G. A propaganda de medicamentos e o mito da saúde. Tese de Mestrado. Escola Nacional de Saúde Pública da Fundação Oswaldo Cruz. Rio de Janeiro: 1984.
20 UZAWA, H. Note on the existence of an equilibrium for $a$ Competitive Economy. Departament of Economics. Stanford University, 1976.

21 von NEUMANN, J. Theory of Games and Economic Dehavior. Pricenton University Press, 1974. 